\title{
HOW INCORPORATING DELIBERATE PRACTICE IN WORK PLACEMENT MAY CONTRIBUTE TO DEVELOPING EXPERTISE IN TRANSLATORS
}

\author{
AGATA SADZA \\ University of Łódź, Poland \\ agata.sadza@uni.lodz.pl
}

\begin{abstract}
The article explores some of the ways in which work placement that accompanies or follows academic instruction may contribute to stimulating trainee translators' professional development. Inspired by general and profession-specific concepts and components of expertise proposed by researchers in the field of cognitive sciences and translation studies as well as her own experience as a translator, translation trainer, and work placement mentor, the author presents some of her observations and preliminary highlights of her ongoing research to emphasise how individualised support for trainees' conscious effort in the course of work placement in a translation company may help novice translators hone their skills and at the same time assume responsibility for their own development, thus empowering them and setting them on track to become experts. In her considerations, the author refers to the minimal concept of translation expertise propounded by Muñoz Martín (2014) and to the notion of deliberate practice as posited by Ericsson et al. (1993) to propose how deliberate practice may be implemented as one of the significant elements of translation work placement in a student-centred course of learning, where various aspects of the actual workplace setting contribute to increased readiness for conscious effort in trainees. This paper may prove of use to translator trainers as well as work placement mentors/coordinators, both on the part of the academic institution, and within the organisation accepting trainees, when they shape or revise their curricula or work placement agendas.
\end{abstract}

Keywords: translation work placement, translation internship, deliberate practice, translator training, translation expertise

\section{Introduction}

Why focus on the development of human translation expertise in the age of unprecedented progress of digital technologies? Indeed, these days, as we are witnessing the rapid development of artificial intelligence, neural machine translation being one of its applications, the profession of translation might seem to be doomed to extinction. On the other hand, the global village we are living in is characterised by so many dynamically interconnected variables which influence 
the language and communication that there are still plenty of situations in which human translators perform better than machines. ${ }^{1}$ Moreover, at least some translation clients, while they are well aware of the time- and cost-efficiency of MT, refuse to switch to automated translation or even explicitly forbid the use of any kind of MT tools by translation service providers, insisting on human-only translation, especially in the case of texts they find crucial for their business operations, such as legal documents, documentation containing proprietary information, key communications and marketing content etc. It arises from author's observations and interviews with translation clients that some of the features that seem to drive their preference for human translation are confidentiality, creativity, reliable knowledge and experience, as well as human translator's availability to accept client's brief/guidelines and answer questions related to the source and target text (especially in transcreation and other tasks which go beyond pure translation). ${ }^{2}$ These characteristics add up to form the perception of a human translator as a knowledgeable, trustworthy individual, who is ready to adjust, or adapt, their performance (including both the product and the process) to the translation task, as needed. Therefore, supporting the development of adaptive expertise in translators (see Hatano and Inagaki 1986 and Section 2 below) may help them, and the translation profession in general, survive the turmoil of digitalisation.

With this in mind, the author draws on her experience as a translator, translation company manager and insider observer of the translators' community on the one hand, and a university translation trainer on the other hand, and integrates the practical understanding of the subject with the selected findings of existing research in the field of expertise from the general, cognitive perspective and also, more specifically, in the domain of translation studies seen as an interdisciplinary field. Some preliminary highlights of author's own research and observations as a work placement mentor are set against this background in an attempt to present the case for making the most of translation work placement and including deliberate practice as one of the core components thereof, with a view to supporting the development of expertise in novice translators.

\footnotetext{
${ }^{1}$ See e.g. Maučec \& Donaj 2019, Castilho et al. 2017.

${ }^{2}$ Practical observations motivated the author to start (in 2020) a research project aimed to study translation clients' awareness of the translation process and expertise. The project follows the spirit of action research and involves in-depth, unstructured interviews with EN $<>P L$ translation clients based in Poland. Research questions focus on clients' perception of the translator as a professional, their knowledge of the translation process, and how these affect their choices when it comes to ordering translation services.
} 


\section{Expertise}

The last century has brought truly extensive research on what expertise is and how it is developed, offering a variety of definitions and approaches, both in general terms and in almost every domain of knowledge.

Over all those years, the view of expertise has evolved to include more and more cognitive concepts. A few decades ago, studies of expertise focused on intelligence and knowledge, and an expert was seen as the one who "sees the underlying principle", thanks to the "richly organized structure of [their] knowledge" (Chi et al. 1981: 108). Researchers recognised the development from declarative knowledge in novices to procedural knowledge in experts, positing that the way to improvement is "through the exercise of procedural (problemsolving) knowledge in the context of specific, knowledge domains" (Ibid: 114), but still omitted or even explicitly excluded the significance of the cognitive component, for instance by stating that "the problem-solving difficulties of novices can be attributed mainly to inadequacies of their knowledge bases, and not to limitations in either the architecture of their cognitive systems or processing capabilities" (Ibid: 112). Much of research of that time centred on the comparison of novices and experts - as a result, it was noticed that there are certain concepts or "components of the cognitive structures that tend to be present in all experts" in a given field (Schvaneveldt et al. 1985: 722) that make experts' performance in their specific domain superior to the performance of many other people in the same field (a similar definition of expertise involving consistently superior performance is presented by Ericsson \& Charness 1994).

Around the same time, Hatano and Inagaki (1984) revisited Piaget's idea of how people develop new skills at a young age, driven by intrinsic motivation to comprehend the world, and posited that there exist two types of expertise: routine expertise and adaptive expertise, both involving some domain-specific knowledge and adequate performance in familiar situations, but different when it comes to changed conditions. Routine experts are fast, accurate and efficient, displaying automatised performance, but lacking flexibility when faced with new problems. On the other hand, adaptive experts are described as "those who not only perform procedural skills efficiently but also understand the meaning of the skills and nature of their object expertise", because they "can construct corresponding conceptual knowledge by performing a procedural skill, and with that conceptual knowledge they can be flexible and adaptive, e. g., 'invent' other procedural knowledge." (Hatano and Inagaki 1984: 28, 30). Interestingly, in the same work the authors refer to their own earlier research project involving translation [sic!], in which they noticed the link between external reinforcement and students focusing strongly on efficiency, but failing to try to understand the text and render a coherent and understandable target language version. They point out that "overemphasis on giving right answers and making no errors (...) may prevent students from constructing conceptual knowledge and thus from becoming 
adaptive experts" (Ibid: 34 ) - a conclusion that seems to be worth remembering when it comes to training translators and evaluating their work.

The concept of adaptive and routine expertise as propounded by Hatano and Inagaki has become widely accepted by scholars working in various fields. It has been explored in further scholarly considerations, e.g. by Ward et al. (2018), who concluded that adaptive skill is an indispensable ingredient of expertise, and in various research projects, e.g. by Bohle Carbonell et al. (2014), who posited, based on their findings, that a flexible knowledge base, which is characteristic of an adaptive expert, develops best in a working environment which offers a variety of tasks. Thus, they made the following suggestion as regards training professionals:

\begin{abstract}
Novelty in the form of unfamiliar tasks can be introduced after an initial level of efficiency in the domain has been achieved. Learners should be stimulated to explore these tasks, solve them with limited scaffolding, and reflect on their errors. Such novel tasks should re-occur at irregular intervals and "...create occasional impasses which confront the learners with situations where the [learned] routines do not work and which train them to switch from an automatic to a problem-solving mode" (van Merriënboer \& Kirschner 2013). The trainer should pay attention to creating a risk free and supportive environment. Summative assessment should be minimalized to strengthen a positive learning climate. In informal learning settings, it is important to create a learning climate through supportive superiors and peers and to stimulate professionals to take on new tasks outside of their current job descriptions. (Bohle Carbonell et al. 2014: 21)
\end{abstract}

The recommendation quoted above seems to be a good supplement to what is propounded in this paper in terms of work placement that is intended to help novice translators hone their skills and at the same time assume responsibility for their own development, thus empowering them and setting them on track to become experts.

\title{
2.1. Deliberate practice
}

When discussion shifts from pondering on what expertise is to how to develop it, deliberate practice is one of the best described elements of the journey. It is attractive to scholars, teachers and trainers alike, as it appears to be a rather "tangible", measurable ingredient of expert development, one which leaves the responsibility for learning with the learner, but still remains monitored and influenced by the instructor. The core assumption of deliberate practice that underpins the view that it is one of the key components of expertise and its development is that it is not simply by repetition, but by effortful practice aimed at improvement that progress can occur. In their breakthrough study on the development of expertise, Ericsson et al. state:

Throughout development toward expert performance, the teachers and coaches instruct the individuals to engage in practice activities that maximize improvement. Given the cost of individualized instruction, the teacher designs practice activities that the individual can engage in between meetings with the teacher. We call these practice activities deliberate 
practice and distinguish them from other activities, such as playful interaction, paid work, and observation of others, that individuals can pursue in the domain. (Ericsson et al. 1993: 368)

The distinction between work and deliberate practice is of particular importance to this paper, as it seems that work placement might be a perfect setting for deliberate practice activities, the latter being defined as neither full-blown work (rewarded by remuneration and/or social recognition) nor play (purely enjoyable, effortless). To support their argument to separate deliberate practice from work, Ericsson et al. (1993) reason that in the case of paid work, only a small range of tested and proven, "previously well-entrenched methods" is typically used, mainly for reasons of time efficiency and to reduce the risk of costly failure. Learning or development of new methods in an attempt to increase the quality of work or make it more efficacious is not a priority. As a result, workers are often pulled into routine and do not improve their performance, as long as it is satisfactory from the employer's perspective. Contrary to that, deliberate practice undertaken on a regular basis pushes forward the one who engages in it, as it allows for "repeated experiences in which the individual can attend to the critical aspects of the situation and incrementally improve her or his performance in response to knowledge of results, feedback, or both from a teacher" (Ibid: 368). Further, Ericsson et al. define deliberate practice as:

a highly structured activity, the explicit goal of which is to improve performance. Specific tasks are invented to overcome weaknesses, and performance is carefully monitored to provide cues for ways to improve it further. (Ericsson et al. 1993: 368)

Ericsson has continued to explore the subject of expertise and the role of deliberate practice as one of its essential elements and expanded on his concept (see e.g. Ericsson et al. 1994, 1996, 2002). His approach proposed a new explanation of how one becomes an expert, which differed noticeably from the previously predominant view, because it lessened the role of what might be called innate talent in the development of expertise understood as "consistently superior performance" (Ericsson 1994: 731) Once announced, Ericsson's notion of deliberate practice stirred a lot of interest not only among researches, teachers and trainers, but also among the general public, being a promise of new, exciting opportunities for all these groups. Consequently, this line of research has since been pursued by many other scholars in relation to various domains, including translation (see below). In a number of works, varying interpretations of the original definition have been applied, and in a few cases doubt has been expressed as to what deliberate practice does or does not involve. One example of the latter, particularly relevant for this work, is the study undertaken by Tiselius (2013), in which at some point she wondered whether certain activities undertaken by professional interpreters she interviewed could be included within the framework of deliberate practice as posited by Ericsson or not, as they were not labelled by the subjects of research as deliberate practice and were performed with a view to 
improving some specific sub-skills (as opposed to the main skill). There has also been a group of scholars who have expressed their criticism or doubt regarding Ericsson's idea of deliberate practice, claiming that it was not sufficiently grounded in research and as such would not be able to account for individual differences in expert performance (see e.g. Hambrick et al. 2013, Macnamara 2016). Ericsson clarified and defended his concept in his elaborate responses to criticism and questions about the scope of application of his theory (Ericsson 2014, Ericsson \& Harwell 2019), which facilitates further research on expertise and deliberate practice and the implementation of deliberate practice activities in training professionals.

\section{Translation studies}

In the present time of advanced globalisation more than ever depends on the communication between users of different languages. Therefore, substantial research effort is put in attempts to understand various problems related to translation, one of them being to find the most efficient ways to teach translation and train translators as intermediaries between cultures and individuals and facilitators of trans-border and interpersonal exchange and communication.

The above means that, while a part of research in translation studies is traditionally centred around text-related problems, there are plenty more subfields in this truly comprehensive discipline. This multifacetedness has been appreciated by translation researchers from the very beginning (see e.g. Toury 1980, 1995, Gambier \& van Doorslaer 2010), with many of them explicitly classifying translation studies as an inter- or trans-discipline (see e.g. Snell-Hornby et al. 1994). This view is developed even further e.g. by Edwin Gentzler, who, inspired by his own long practice as a translator, translation teacher and researcher, postulated that "translation today knows no institutional boundaries, and it is time for scholars to catch up to the practice" (Gentzler 2014: 23). In fact, the birth of post-translation studies has already been announced, as "a transdisciplinary research field" where translation is treated as "an interpretive as well as operative tool", while its research is "fundamentally transdisciplinary, mobile, and open ended" (Nergaard \& Arduini 2011: 8).

Considering the above, it comes as no surprise that translation researchers reach out boldly to a whole range of disciplines in pursuit of answers to their research questions, for instance those related to the process of translation and the development of translation expertise, to integrate the data therefrom in their work, often with a truly synergistic effect.

\subsection{Translation expertise}

A significant part of research in the field of translation studies has centred on the investigation of what it is that makes one an expert translator, whether these are 
some universally measurable qualities, and how these can be developed, among others.

For the purpose of studies on translation expertise, researchers follow the trends observed in cognitive sciences and often choose to take a descriptive, process-oriented approach rather than (or in addition to) a product-oriented one, because it is the in-depth analysis and breakdown of the process of translation that reveal to them more about how experts work. As what is happening in translator's head in the course of translation work is not only the matter of language proficiency as such, but also a thing of mental processes that are dependent on a number of factors, translation researchers have turned their attention to cognitive sciences. This led to the emergence of the new sub-discipline of cognitive translation studies, at the intersection of linguistics and other domains, mainly cognitive psychology. Following this direction of research on translation expertise, Ricardo Muñoz Martín set an important milestone in the development of the new sub-field, as he defined the foundations of what he calls cognitive translatology, which assumes that "the mental activity of translators is a constant of all human translation processes" and therefore "translation expertise implies the continuous development of natural cognitive skills" (Muñoz Martín 2010: 177). In this concept, translation is explicitly stated to be seen and studied as "a subset of complex behaviours aiming to solve communicative needs, whose common thread is the use of at least two (spoken, written or signed) languages" (Muñoz Martín 2014: 3). In his further work on this subject, Muñoz Martín continues to argue for the cognitive perspective and proposes a minimal, situated concept of general translation expertise (which he sees as applicable, or at least adaptable to experts in other domains). He lists the following five dimensions of that concept: "knowledge, adaptive psychophysiological traits, problem-solving skills, regulatory skills, and the self-concept" (Muñoz Martín 2014: 1). Such a perspective on translation expertise seems to correspond to the characteristics of adaptive expertise as propounded by Hatano and Iganaki (see Section 2 above). In fact, Muñoz Martín himself concludes:

In translation tasks, where input is never exactly the same and idiosyncratic, ill-defined problems are the norm, only adaptive expertise - characterized by the ability to develop new strategies to cope with novel situations - can be deemed full translation expertise. (Muñoz Martín 2014: 9)

It is worth noting here that Muñoz Martín leaves language skills out of his list, seeing them as something that is obviously there, a pre-requisite for developing translation expertise. He argues that "rather than explaining translation expertise, language skills seem to sustain it, and to interact with it", and that in fact, bilingual proficiency is one of the relatively many (in comparison to other fields of expertise) skills in translators and interpreters that are "further developments of previously existing skills.” (Muñoz Martín 2014: 17) 
This last assertion is very important not only for translation researchers, but also for translation trainers, as it may be derived from it that it is crucial for the development of translation expertise to focus on advancing the already present and used skills rather than on learning new skills from the scratch. It being so, we need to remember that - just like in the case of learning anything else - there are some points along the way, called plateaus (see e.g. Collins et al. 1973: 157), when the learning curve starts to flatten. This may happen for instance once the initial excitation shrinks, and also when the level achieved so far is already sufficient for the learner to use the skill autonomously, even if far from expertly. If learning and development are not to end at this autonomous-but-not-yet-expert point, substantial conscious effort is needed on the part of the learner to proceed with learning despite the motivation loss that they may experience. As stated above, it is predominantly "old" skills that are improved in the process of developing translation expertise, so it may be concluded that the development of expertise in translators involves trainees' conscious effort in order to progress through plateaus. This in turn means that deliberate practice, being conscious, effortful and aimed to improve a concrete skill, may be an important element of translator training, including translation work placement.

\subsection{Deliberate practice in the development of translation expertise}

Having been widely discussed in various fields, such as professional sports, medicine and music, deliberate practice has recently gained interest in the field of translation studies, too (see e.g. Shreve 2006, Tiselius 2013, Kiraly \& Piotrowska 2014, Risku 2016). As its objective is to forward the development of expertise in professionals, it seems to be a good idea to consider incorporating it in the translator training framework, including work placement. If deliberate practice is offered to trainees not only in the classroom, but also as part of their translation work placement, it may enhance the development of various dimensions of translation expertise in them, supporting the trainees in breaking through plateau stages they may experience when striving to improve the skills that are already present in them and used autonomously - all that in the actual workplace setting. In section 4.1. below, where various benefits of work placement are demonstrated, as observed by the author from her experience as a work placement mentor and supported by selected trainees' statements, ${ }^{3}$ a reference is made to the particular dimensions of the model of translation expertise posited by Muñoz Martín. First, however, some general assumptions regarding work placement are presented.

\footnotetext{
${ }^{3}$ Selected fragments of interviews with translation trainees held as part of author's ongoing research project on the role of workplace placement in novice translator's journey to expertise - for more details, see below.
} 


\section{Work placement}

Following long years of research on how people acquire and develop skills, and the related studies on learning and teaching, it has already become a widely accepted view that "learning is a holistic, emergent, self-perpetuating and embodied lifelong process that proceeds both within the individual and within communities of practice at different levels" (Kiraly \& Piotrowska 2014: 4). It being so, education has turned to be more process- and student-oriented than ever, also in the field of translation studies, with situated learning gaining prominence as the form of classroom work that is as practical as possible in the academic context. Furthermore, researchers' and teachers'/trainers' appreciation of and interest in the actual "real-life" professional practice seems to be concurrent with the generally observed willingness of the non-academic world to attract and cultivate new potential talents while they are still students, supported by numerous projects aimed at tightening the links between business and academia. This might be a good moment to revisit the long-known concept of internship/work placement and make sure the trainee's professional development is supported there as much as possible.

For the sake of clarity, it deserves to be noted here that, depending on the country, university, field of study/work or business sector, the terms "internship" and "work placement" and other similar notions are either treated as synonyms or they are used in slightly different senses, "work placement" sometimes denoting a longer, e.g. year-long, paid stay with the company, as opposed to "internship" being a shorter, unpaid period of student's workplace practice. For the purpose of these considerations, the author does not differentiate between in- or extracurricular, paid or unpaid students' work experience, and she uses the terms "work placement" and "internship" interchangeably, in a wide, general sense, to denote all kinds of students' work experience undertaken to accompany university programmes. In the case of translation work placement as referred to in this paper, this involves a student of translation being introduced as a trainee translator into the real-life environment of a translation company for at least 150 hours, under the supervision of an experienced practitioner being their work placement mentor. Formal issues are omitted here for the lack of space, and because for the present considerations the most important aspect of work placement is the fact of students' gaining hands-on translation work experience before entering the professional translation market, complementary to the academic instruction and classroom practice in the course of their translation study programme.

Possible benefits to the trainees' development resulting from being placed "within communities of practice" (Ibid), which gives them a unique opportunity to watch and participate in the professional work of experienced practitioners, are not the only advantages of work placement. Literature on the subject demonstrates that there exists a positive relationship between students' work placement experience and how they are perceived by potential employers, which translates into the higher interview rate in the case of students with on-the-job experience 
(see e.g. Nunley et al. 2016, Baert et. al. 2021). When Inceoglu et al. presented their theoretically framed systematic review of literature, they quoted various figures from market- and practice-oriented reports which confirm the substantial relationship between students' work experience and their subsequent employability, and observed that "work placements or internships provide opportunities for 'trial transitions' to the world of work, given their structured and educationally embedded set up" (Inceoglu et al. 2019: 318). This seems to hold true for translation work placement, too.

\subsection{Translation work placement}

If - as may be driven from what Muñoz Martín (2014) proposed - the road to translator's expertise mainly involves work on the successive improvement of skills that already exist in a trainee or novice translator and are used by them, then twofold consequences for their learning and progress may be expected in the course of professional education. Firstly, individuals headed to become professional translators may experience the discouragement and lack of motivation characteristic of the plateau effect before they even approach what might be called expertise. Secondly, sometimes they may find it hard to understand which skills or dimensions of expertise need to be improved and why.

However, as observed by the author of this paper, when trainees become immersed in real-life translation practice and at the same time experience individualised support from the mentor, they seem to open up more willingly, or readily - as compared to the classroom context - to become mindful of the various dimensions of translation expertise, and many of them undertake conscious effort to improve their skills and assume the ownership of their own development. This observation and the informal interviews with trainees led the author to start in 2020 a research project aimed to check in what ways translation work placement may contribute to the development of translation expertise in novice translators. Data are collected from respondents (students/novice translators, workplace mentors) in interviews and surveys, in order to find out some possible relations between various aspects of work placement and students' translation performance over time and to trace their post-placement professional development.

Due to the long-term nature of the project, its final conclusions are not available yet, but some preliminary data gathered so far seem to confirm the author's practical observation stated above, i.e. that work placement may be a favourable context for students to engage in mindful effort with a view to achieving translation expertise. This is demonstrated for instance in the following statement of one of the trainees interviewed immediately after the completion of her work placement, as she talked about her problem with punctuation in defining vs. non-defining relative clauses (like many novice Polish translators, she transposed Polish punctuation rules to her translation into English, which resulted in all her relative clauses in English being non-defining): 
It was not until I heard the project manager complaining about someone doing it wrong, and then saw (...) the "real" translator thinking aloud about how a comma will change the meaning in some particularly ambiguous sentence that it finally clicked! Now, after so many years of learning grammar! That was illuminating! I had to find the rule and learn it again, but this time I got it. My mentor gave me some exercises for that and discussed them with me afterwards. I also appreciate it that (...) [she] showed me more sentences like that in other translators' work, whenever [she] spotted a good example in the texts [she was] revising. When it comes to writing or translating, I still sometimes forget about it and simply copy the Polish commas, but I know that I need to check my own work twice for these and I can feel it is getting in my blood, finally. I am going to work on my punctuation in both Polish and English now, to make sure I know all the rules and exceptions. (... $)^{4}$

This trainee's statement is a representative example of a number of similar midand post-placement reflections reported so far by the author's interviewees. It was quoted here, because it allows for a reference to a few dimensions of translation expertise in a relatively short fragment, suitable for the size and concept of this paper. It demonstrates the trainee's newly emergent awareness (new working selfconcept $t^{5}$ ) of the need to refine her understanding of the punctuation rules (i.e. to improve the knowledge), and her willingness to revise and correct her own work (regulatory skills - "conscious, wilful, cognitive monitoring and control" ${ }^{\text {). }}$. Moreover, she engaged willingly in a deliberate practice activity (punctuation exercises supervised by her workplace mentor) and was open to undertake more purposeful practice with a view to improving her performance.

In terms of general remarks regarding the framework of work placement, it seems to be of utmost gravity to design it in such a way that trainees can focus on translation and revision work as their key tasks, have access to feedback, and consult their workplace mentor acting here as their senior peer or tutor, a guide rather than a controlling coordinator. The above are among the top "characteristics of worthwhile work placement experience" indicated before, during and after work placement by most of the trainees surveyed and interviewed by the author so far, regardless of whether their overall assessment of their own work placement experience was positive or not. Interestingly, these characteristics of work placement rank high even among those trainees who claimed in their postplacement surveys that they were definitely not going to pursue a career in translation. This issue was further investigated during in-depth interviews with selected respondents, in which those trainees who stated they were going to opt out of the translation profession emphasised that they still appreciated the characteristics of work placement mentioned above, or even attributed their

\footnotetext{
${ }^{4}$ The interviews with students cited in this paper were held in Polish. The English versions of the fragments cited here were translated by the author, and the translated fragments were then revised and approved by the trainees themselves.

${ }^{5}$ The notion of working/dynamic/activated self-concept, i.e. the self-concept of the moment has been defined and researched by various scholars in the field of social and psychological sciences (e.g. Schlenker 1985, Markus \& Wurf 1987).

${ }^{6}$ Muñoz Martín (2014: 28).
} 
decision to this set of features. One of such interviewees summed up his work placement as follows:

It was a revealing experience leading to a life-changing decision. It's not that I'm not happy with the placement. It's just now I know I definitely don't want to do it. I am good at languages, I can work in some international organisation, but not as a full-time translator. During this work placement I've realised that I don't really like all those "research this term" and "think what the author of the source text might have meant" ponderings and the questions you need to ask yourself, especially that you will need to hold these discussions with yourself once you become a freelancer or even an in-house translator. It was fun, but it's not for me. (...) I think I appreciated how focused you need to be and how you need to be up-to-date with virtually everything in order to recognise some hidden meanings within the source text. I also realised that I am not able to spend so much time sitting. I'd rather do something a bit more dynamic.

This quote presents another (but equally important) perspective on how work placement supports trainees in comprehending what translation expertise involves. When novice translators are given an opportunity to see experts (or at least professionals further down the path towards expertise) struggle, succeed, err and correct themselves, look for linguistic solutions, negotiate meanings, contact their clients and peers (or, on the contrary, they see them fail to do it and experience the consequences thereof) and also observe the work of the remaining stakeholders in the translation process, it is easier for them to verify and adjust their internal concept of what they need themselves to develop into experts. Some of them will probably resign from pursuing the translation path. However, those who decide to develop in this field, having experienced during work placement some of the challenges that translator's everyday work involves, may be more willing to engage in further education and training in a focused and purposeful way. This is demonstrated in another quote from an interview with a trainee translator held on the last day of her work placement:

I definitely feel motivated to develop as a translator. I really like it, I want to do it. (...) I can see some things I need to do better, and I've been working on some tasks in order to improve them. For instance yesterday I created three different versions of the same text, but with a different target audience in mind. My workplace mentor suggested it, I am waiting for feedback now. I have a problem with it, because I tend to focus on the language so much that I forget about who is going to read it. (...) I can definitely say that I have started to put my mind into my translation work thanks to such exercises.

This statement reveals the trainee's perception of deliberate practice activities as worthwhile elements of her expertise development. It has been observed by the author that trainees who demonstrate this approach during work placement remain mindful and focused in their further regular professional practice, too. However, this observation needs to be verified in further research.

The author has also noticed - and this observation has been confirmed preliminarily in the interviews held so far as part of the ongoing research project 
referred to here - that the trainees who were invited to participate actively and onsite in the translation and revision tasks, but also in other stages of translation project management recognised the fact that they could watch the project manager, translators and revisers at work and participate in the whole translation process as an invaluable opportunity "to see the other side of the mirror", i.e. to observe how some behaviours or strategies applied by translators and other actors in this process are received by other parties (including e.g. those situations between the translation company and the client that never find their way to the translator for a variety of reasons, time efficiency being the main one, but may have influence on how the translator's performance is assessed by their immediate client, i.e. the translation company).

Unfortunately, the general framework of translation work placement design that arises from the above considerations, i.e. supervised translation and revision tasks as the core component plus some project management and administrative tasks as an addition (that takes significantly less time) is not a standard in translation companies accepting trainees for work placement, which has been observed by the author in conversations with her students, in some of her research interviews and as a result of her monitoring various online translators' communities. It is also demonstrated by Maite Gonzalez in her study on whether and how the translation placement curriculum responds to the actual requirements of the market:

If we look at the current industry trends, work placements include mainly project management because first, the assignment of real translation jobs, especially at the beginning of the placement is rejected by some employers, as they believe that the students cannot produce satisfactory translations, something that would displease the client (...). Second, a substantial amount of work is sent to freelance translators. The primary reason has to do with costs and flexibility of resources. Third, many of the current translation companies and agencies have only project managers and project coordinators working in-house; whereas the translations are resourced to freelancers. (Gonzales 2014: 67)

From the perspective of a translation company owner (known to the author of this text from her own experience), for whom offering and managing trainee translators' work placement is a time- and energy-consuming challenge, far more than it is getting free workforce, as some outsiders like to think, it is hard to disagree with the summary of the situation offered by Gonzales in the quote above and in the following conclusion she makes:

There seems to be a general impression from both students and employers that the work placement equips students with further knowledge of the industry but it does not necessarily develop their translation skills. Work placement reports, job descriptions and interviews from employers and students demonstrated that most students doing placements in house were involved in activities such as project management, administration, recruitment but not translation. The findings also demonstrated that internships give students the opportunity to gain a deeper knowledge of how a translation company works and to establish links with the 
industry; but again students have limited opportunities to practise translation. (Gonzales 2014: 67)

Still, if these grim reflections on the chasm between "what it should be" and "what it is" are ever to become a thing of the past, it needs to be remembered by those involved in translation training, designing work placement curricula and accepting trainees for internship in their organisations that:

If 'learning to be a professional translator means learning to act like one' (Kiraly in: Pym, 2003:29) the sooner students come into direct contact with professionals, the better they will know how to deal with the difficulties of the professional world" (Cravo \& Neves 2007: 100).

With this in mind, the author of this paper remains hopeful that the potential of work placement in translator education will be appreciated and maximised by all those involved. In an attempt to contribute to that, she intends to investigate the subject of translation work placement in her ongoing and further research.

\section{Conclusions}

When the practical observations of a workplace mentor and translation trainer, supported by some preliminary input from author's ongoing research, are set against the theoretical framework of expertise in general, and also translation expertise as seen from the interdisciplinary perspective of translation studies, it seems reasonable to conclude that translation work placement with elements of deliberate practice may contribute to the development of translation expertise. It is an exceptional opportunity to support novice translators along their path towards translation expertise, help them break through plateau stages, but also prepare them to face the variety of translation challenges while remining mindful and self-reflective.

The subject of translation expertise and its development still offers a broad field for a variety of studies. One particular area that deserves scholarly attention in this respect is the very interface of academia and professional practice. More research into various aspects of translation work placement experience as seen from the perspective of various stakeholders (trainees, workplace mentors, employers, university teachers) might provide knowledge and data to facilitate synergistic cooperation between those parties and thus enhance the development of novice translators' expertise, but also influence, if indirectly, the efficiency of institutional work. Further in-depth, longitudinal research on the post-study development of translation expertise is needed to trace the long-term effect of the work placement experience and deliberate practice activities undertaken in the process on professional translator's approach to lifelong development and the quality of their work. 


\section{References}

Baert, Stijn \& Neyt, Brecht Siedler \& Thomas, Tobback \& Ilse Verhaest, Dieter. 2021. Student internships and employment opportunities after graduation: A field experiment. [Online] Economics of Education Review, Volume 83, August 2021, 10214. Available from: https://doi.org/10.1016/j.econedurev.2021.102141 [Accessed: $12^{\text {th }}$ July 2021].

Bohle Carbonell, Katerina \& Stalmeijer, Renée E. \& Könings, Karen D. \& Segers, Mien \& van Merriënboer, Jeroen J.G. 2014. How experts deal with novel situations: A review of adaptive expertise. Educational Research Review, Volume 12 (2014). 14-29. [Online]. Available from: https://doi.org/10.1016/j.edurev.2014.03.001. [Accessed: 1st August 2021].

Castilho, Sheila \& Moorkens, Joss \& Gaspari, Federico \& Calixto, Iacer \& Tinsley, John \& Way, Andy. 2017. Is Neural Machine Translation the New State of the Art? The Prague Bulletin of Mathematical Linguistics. [Online] Available from: https://doi.org/108. 109-120. 10.1515/pralin-2017-0013. [Accessed: 12 August 2021].

Chi, Michelene T. H. \& Glaser, Robert \& Rees, Ernest. 1981. Expertise in Problem Solving. Learning Research and Development Center, University of Pittsburgh. [Online]. Available from: https://files.eric.ed.gov/fulltext/ED215899.pdf. [Accessed: 1st August 2021].

Collins, K.T. et al. 1973. Key words in education. Longman.

Cravo, Ana \& Neves, Josélia. 2007. Action Research in Translation Studies. The Journal of Specialised Translation, Issue 7, January 2007. 92-107. [Online] Available from: https://www.jostrans.org/ [Accessed: $20^{\text {th }}$ July 2021].

Ericsson, Karl \& Krampe, Ralf \& Tesch-Roemer, Clemens. 1993. The Role of Deliberate Practice in the Acquisition of Expert Performance. Psychological Review. 100(3). 363-406. [Online] Available from: https://doi.org/10.1037/0033-295X.100.3.363 [Accessed: $20^{\text {th }}$ July 2021].

Ericsson, Karl \& Charness, Neil. 1994. Expert Performance: Its Structure and Acquisition. American Psychologist. 49. 725-747. [Online] Available from: https://doi.org/10.1037/0003066X.49.8.725. [Accessed: $20^{\text {th }}$ July 2021].

Ericsson, Karl \& Lehmann, Andreas. 1996. Expert and exceptional performance: evidence of maximal adaptations to task constraints. Annual Review of Psychology 47(1). 273-305. [Online] Available from: https://doi.org/10.1146/annurev.psych.47.1.273. [Accessed: $20^{\text {th }}$ July 2021].

Ericsson, Karl. 2002. Attaining Excellence Through Deliberate Practice: Insights from the Study of Expert Performance. In Michel Ferrari (ed.) The Pursuit of Excellence Through Education. Lawrence Erlbaum Associates, Publishers. 21-55

Ericsson, Karl. 2014. Why expert performance is special and cannot be extrapolated from studies of performance in the general population: A response to criticisms. Intelligence, 45 (2014). 81103. [Online] Available from: https://doi.org/10.1016/j.intell.2013.12.001. [Accessed: 20th July 2021].

Ericsson, Karl \& Harwell, Kyle W. 2019. Deliberate Practice and Proposed Limits on the Effects of Practice on the Acquisition of Expert Performance: Why the Original Definition Matters and Recommendations for Future Research. Frontiers in Psychology, Volume 10/2019. [Online] Available from: https://doi.org/10.3389/fpsyg.2019.02396. [Accessed: 20 ${ }^{\text {th }}$ July 2021].

Gambier, Yves. 2010. Translation strategies and tactics. In Yves Gambier, Luc van Doorslaer (ed.) Handbook of Translation Studies vol. 1. 412-418. John Benjamins Publishing Company,

Gentzler, Edwin. 2014. Translation Studies: Pre-Discipline, Discipline, Interdiscipline, and PostDiscipline. International Journal of Society, Culture \& Language, 2, Issue 2 (Special Issue on Translation, Society \& Culture), 2014. 13-24.

Gonzalez, Maite. 2014. Changing Perspectives: aligning the placement curriculum with current industry needs. Investigations in university teaching and learning, 9. 61-69. [Online] Available from: http://repository.londonmet.ac.uk/id/eprint/333 [Accessed: 20th July 2021].

Hambrick, Zach \& Oswald, Frederick \& Altmann, Erik \& Meinz, Elisabeth \& Gobet, Fernand \& Campitelli, Guillermo. 2013. Deliberate practice: Is that all it takes to become an expert? 
Intelligence, 45 (2014). 34-35. [Online] Available from:

https://doi.org/10.1016/j.intell.2013.04.001. [Accessed: 20th July 2021].

Hambrick, Zach \& Oswald, Frederick \& Altmann, Erik \& Meinz, Elisabeth \& Gobet, Fernand \&

Campitelli, Guillermo. 2013. Accounting for expert performance: The devil is in the details.

Intelligence, 45 (2014). 112-114. [Online] Available from:

https://doi.org/10.1016/j.intell.2014.01.007. [Accessed: 20th July 2021].

Hatano, Giyoo \& Inagaki, Kayoko. 1984. Two Courses of Expertise. In RESEARCH AND CLINICAL CENTER FOR CHILD DEVELOPMENT Annual Report. Volume 6. 27-36. [Online] Available from: http://hdl.handle.net/2115/25206. [Accessed: 20th July 2021].

Inceoglu, Ilke \& Selenko, Eva \& McDowall, Almuth \& Schlachter, Svenja. 2019. (How) Do work placements work? Scrutinizing the quantitative evidence for a theory-driven future research agenda. Journal of Vocational Behavior, Volume 110, Part B, 2019. 317-337. [Online] Available from: https://doi.org/10.1016/j.jvb.2018.09.002. [Accessed: 22nd July 2021].

Kiraly, Don \& Piotrowska, Maria. 2014. Towards an Emergent Development Curriculum Development Model for the European Graduate Placement Scheme. In Pixel (ed.) Conference Proceedings. The Future of Education. 4th Edition. libreriauniversitaria.it Edizioni. 368-373. [Online] Available from: https://books.google.pl. [Accessed: 22nd July 2021].

Macnamara, Brooke N. \& Moreau, David \& Hambrick, David Z. 2016. The relationship between deliberate practice and performance in sports: a meta-analysis. Perspectives on Psychological Science 11.333-350. [Online] Available from: https://doi.org/10.1177/1745691616635591. [Accessed: 20th July 2021].

Markus, Hazel \& Wurf, Elissa. 1987. The Dynamic Self-Concept: A Social Psychological Perspective. Annual Review of Psychology. 1987.38. 299-337

Maučec, Mirjam \& Donaj, Gregor. 2019. Machine Translation and the Evaluation of Its Quality. [Online] Available from: https://doi.org/10.5772/intechopen.89063 [Accessed: 12 August 2021].

Muñoz Martín, Ricardo. 2010. On paradigms and cognitive translatology. In Gregory Shreve \& Erik Angelon (ed.) Translation and Cognition. 169-187. John Benjamins.

Muñoz Martín, Ricardo. 2014. Situating Translation Expertise: A Review with a Sketch of a Construct. In John W. Schwieter, Aline Ferreira (ed.) The development of translation competence: Theories and methodologies from psycholinguistics and cognitive science. Cambridge Scholars Publishing. 2-56.

Nergaard, Stefano \& Arduini, Siri. 2011. Translation: A new paradigm. Translation: An interdisciplinary Journal, inaugural issue, 8-17. [Online] Available from: academia.edu. [Accessed: 20th July 2021].

Nunley, John, M. \& Pugh, Adam \& Romero, Nicholas \& Seals, Alan, R., Jr. 2016. College major, internship experience, and employment opportunities: Estimates from a Resume audit. Labour Economics. Volume 38, January 2016. 37-46. [Online] Available from: https://doi.org/10.1016/j.labeco.2015.11.002. [Accessed: 12th July 2021].

Pym, Anthony et al. 2003. Innovation and e-learning in translator training. Torragona: Intercultural Studies Group \& Universitat Roviva I Virgili.

Risku, Hanna. 2016. Situated learning in translation research training: academic research as a reflection of practice. The Interpreter and Translator Trainer, 10:1. 12-28. [Online] Available from: https://doi.org/10.1080/1750399X.2016.1154340. [Accessed: 20th July 2021].

Schlenker, Barry R. 1985. Identity and self-identification. In B. R. Schlenker (ed.), The self and social life. New York: McGraw-Hill. 65-99.

Schvaneveldt, Roger W. \& Durso, Francis T. \& Goldsmith, Timothy E. \& Breen, Timothy J. \& Cooke, Nancy M. \& Tucker, Richard G. \& C. De Maio, Joseph. 1985. Measuring the structure of expertise. International Journal of Man-Machine Studies. Volume 23, Issue 6, 1985. 699728.

Shreve, Gregory. 2006. The Deliberate Practice: Translation and Expertise. Journal of Translation Studies 9 (1) (2006). 27-42. 
Snell-Hornby, Mary \& Pöcchacker, Franz \& Kaindl, Klaus (ed.) (1994). Translation Studies. An Interdiscipline. Amsterdam / Philadelphia: John Benjamins.

Tiselius, Elisabet. 2013. Expertise without Deliberate Practice? The case of simultaneous interpreters. The Interpreters' Newsletter. 18. 1-15.

Toury, Gideon. 1980. In Search of a Theory of Translation. Tel Aviv: Tel Aviv University, the Porter Institute for Poetics and Semiotics.

Toury, Gideon. 1995. Descriptive Translation Studies and Beyond. Amsterdam/Philadelphia: John Benjamins.

Ward, Paul \& Gore, Julie \& Hutton, Robert \& Conway, Gareth E. \& Hoffman, Robert R. 2018. Adaptive Skill as the Conditio Sine Qua Non of Expertise. Journal of Applied Research in Memory and Cognition, Volume 7, Issue 1,2018. 35-50. [Online] Available from: https://doi.org/10.1016/j.jarmac.2018.01.009. [Accessed: 12th August 2021]. 